\title{
Prototipe Mesin Pengekstrak Pati Sagu Tipe Stirrer Rotary Blade Bertenaga Pedal
}

\section{Prototype of Pedal Power Stirrer Rotary Blade Type ofSago Starch Extraction Machine}

\author{
Darma $^{1 *}$, Bertha Mangallo ${ }^{2}$, Charles Rumere ${ }^{1}$ \\ ${ }^{1}$ Jurusan Teknologi Pertanian, Universitas Papua, Jl. Gunung Salju amban, Manokwari 98314 \\ ${ }^{2}$ Jurusan Kimia, Universitas Papua, Jl. Gunung Salju amban, Manokwari 98314 \\ *Email: darmabond@gmail.com
}

\begin{abstract}
Traditional method of sago starch extraction was inefficient and ineffective, it is a time and labor intensive process. Consequently, sago starch production and utilization especially in Papua and West Papua province are very low comparing with its potential. Millions of tons of the starch contained in the sago trunk was not harvested and disappear every year. Farmers in this area continue to use traditional systems to process sago starch because the lack of mechanical equipment. The objective of this research was to design and performance test of stirrer rotary blade type sago starch extraction machine powered by pedal. The machine consists of 5 main components i.e. (a) Extraction cylinder which is facilitated with screen, (b) Power transmission mechanism, (c) Main Frame (d) Flowing pipe and (e) Stirrer blades. In the experiment, three levels of driver pulley and driven pulley ratio i.e. 6:1, 4:1 and 3:1 and 3 levels of stirring time period i.e. 5, 10 and 15 minutes were examined. The machine performance test was carried out by measuring extraction capacity, starch percentage, starch yield, and starch present in sago pith waste. Results showed that the shorter the extraction duration time, the higher the performance, while the higher the ratio of driver to driven pulley the higher the performance. The best condition to achieve highest performance was 5 minutes with the ratio of driver to driven pulley 6:1. The machine performance at the condition were (a) extraction capacity 120 kg/hour, (b) starch percentage $20.6 \%$, (c) Starch yield $24.6 \mathrm{~kg} / \mathrm{hour}$ and (d) Starch present in waste $0.3 \%$.
\end{abstract}

Keywords: extraction machine, pedal power, stirrer rotary blade, sago starch

\begin{abstract}
Abstrak
Ekstraksi pati sagu secara tradisional tidak efektif dan tidak efisien, dan sebagai konsekuensinya sebagian besar pohon sagu yang telah siap dipanen milik masyarakat terutama di Provinsi Papua dan Papua Barat dibiarkan terbuang begitu saja oleh pemiliknya. Masyarakat di daerah tersebut masih menggunakan pengolahan secara tradisional karena kekurangan peralatan mekanis. Jutaan ton pati yang terkandung pada batang sagu tidak dimanfaatkan dan terbuang sia-sia setiap tahunnya. Tujuan penelitian ini adalah mendesain dan menguji kinerja prototype mesin ekstraksi pati sagu tipe stirrer rotary blade bertenaga pedal. Mesin ini terdiri dari 5 komponen utama yaitu (a) Tabung ekstraksi yang dilengkapi dengan saringan, (b) Komponen transmisi daya, (c) Rangka utama,(d) Pipa penyalur suspensi pati dan (e) Pengaduk . Pada penelitian ini digunakan 3 taraf ratio driver pulley:driven pulley yaitu 6:1, 4:1 dan 3:1 yang diuji pada 3 level periode waktu ekstraksi yaitu 5, 10 dan 15 menit. Evaluasi kinerja dilakukan dengan mengukur variabel (a) Kapasitas ekstraksi, (b) Rendemen pati, (c) Hasil pati dan (d) Persentase pati pada ampas. Hasil pengujian kinerja mesin menunjukkan bahwa semakin lama periode waktu ekstraksi, semakin rendah kinerjanya, sebaliknya semakin besar ratio driver pulley:driven pulley maka semakin tinggi kinerja mesin. Kinerja tertinggi diperoleh dengan menggunakan ratio 6:1 pada periode waktu ekstraksi 5 menit. Kinerja mesin pada kondisi tersebut adalah (a) Kapasitas ekstraksi $120 \mathrm{~kg}$ ela/jam, (b) Rendemen pati 20,6 \%, (c) Hasil pati $24.6 \mathrm{~kg} / \mathrm{jam}$ dan (d) Persentase pati pada ampas $0.3 \%$.
\end{abstract}

Kata kunci: mesin pengekstrak, hasil pati, stirrer rotary blade, pati sagu, tenaga pedal 


\section{PENDAHULUAN}

Walaupun Papua dan Papua Barat memiliki potensi sagu sangat besar, namun sampai saat ini produksi dan pemanfaatan pati sagu masih sangat rendah jika dibandingkan dengan potensi produksi yang ada. Jutaan ton pati yang terkandung dalam batang sagu tidak dipanen hilang percuma setiap tahunnya. Diperkirakan potensi produksi pati basah di Papua adalah 9.070.145-33.102.720 ton/tahun atau setara dengan 5.638.579 - 20.706.496 ton pati kering per tahun. Menurut Bintoro (2011), potensi produksi sagu alam berkisar antara 20-40 ton pati/ha/tahun. Hal ini berarti bahwa potensi produksi pati sagu di Papua dan Papua Barat adalah 29.424.640 58.849.280 ton/tahun. Hasil penelitian Jong dan Ho (2011) menyimpulkan bahwa potensi produksi hutan sagu alam di Papua adalah antara $10-15$ ton pati kering/ha/tahun, dengan demikian potensi produksi total adalah antara $14.712 .320-22.068 .480$ ton pati kering/tahun. Namun demikian, Matanubun dan Maturbong (2006) memperkirakan bahwa pemanfaatan sumberdaya sagu di Papua kurang dari 5\% dari potensi yang ada. Rendahnya produksi ini terutama disebabkan karena sebagian besar pengolahan sagu dilakukan oleh masyarakat secara tradisional, dan juga karena lokasi areal sagu umumnya terletak di daerah marginal dengan kondisi geografi dan demografi yang tidak menunjang dengan sarana produksi yang terbatas.

Pada pengolahan secara tradisional, tahapan yang membutuhkan waktu paling lama yaitu penghancuran empulur (penokokan) disusul ekstraksi (peremasan), sedangkan kegiatan lainnya curahan waktunya tidak begitu significant. Rata-rata waktu yang diperlukan untuk penokokan adalah 53,22 \% dari total waktu yang diperlukan untuk pengolahan, dan 38,92\% untuk peremasan. Dengan demikian sebagian besar waktu untuk pengolahan $(92,14 \%)$ tercurah untuk kedua kegiatan ini (Darma, 2011). Penerapan teknologi mekanis dalam bentuk mesin dan peralatan mekanis tepat guna (Appropriate Technology) di kalangan petani sangat tepat untuk dikembangkan agar jumlah dan mutu produk dapat ditingkatkan. Persyaratan dari teknologi dimaksud adalah mudah dibuat, mudah dioprasikan, sederhana, praktis, efisien dan mudah diadopsi oleh petani karena harganya terjangkau.

Pada penelitian-penelitian sebelumnya, Darma dkk., (2009; 2010; 2013; 2014; 2017) telah dihasilkan prototype alat pemarut empulur batang sagu yang telah digunakan secara luas oleh masyarakat di Kabupaten Teluk Wondama. Namun pada proses selanjutnya yaitu ekstraksi pati masih dilakukan secara tradisional/manual sehingga terjadi ketidaksinambungan (discontinuity) proses pengolahan. Untuk menanggulangi kendala ini, perlu dirancang mesin/alat pengekstrak pati sagu yang pengoprasiaannya tidak tergantung sepenuhnya pada masukan eksternal, harganya terjangkau di tingkat petani dan efisien dalam penggunaannya.

Tujuan penelitian ini adalah mendesain dan menguji kinerja prototype mesin pengekstrak pati sagu tipe stirrer rotary blade bertenaga pedal. Dari penelitian ini diharapkan akan dihasilkan mesin pengekstrak pati sagu yang yang handal, layak secara tekno-ekonomi, praktis dalam penggunaan, harganya terjangkau, dan sesuai dengan kondisi sociokultural masyarakat setempat.

\section{METODOLOGI}

\section{Waktu dan Tempat}

Pembuatan dan uji kinerja prototype mesin pengekstrak pati sagu dilaksanakan di bengkel mekanisasi pertanian, jurusan Teknologi Pertanian, FATETA UNIPA. Beberapa bagian alat dibuat di bengkel SMK II Manokwari dan bengkel Arema Manokwari yang memiliki fasilitas peralatan memadai. Pengambilan pohon sagu yang diolah untuk pengujian kinerja mesin diambil dari dusun sagu yang terdekat dengan kampus.

\section{Bahan dan Alat}

Bahan-bahan yang akan digunakan pada penelitian ini ialah: Besi siku berukuran $5 \mathrm{~cm} \times 5 \mathrm{~cm} \times 0.5 \mathrm{~cm}$, besi plat ketebalan 2 $\mathrm{mm}$, besi as stainless steel SS 201 diameter $19 \mathrm{~mm}$, besi as stainless steel SS 201 diameter $25 \mathrm{~mm}$, pillow block UCP 204 dan UCP 205, saringan stainless steel SS 304 diameter lubang $0.8 \mathrm{~mm}$, besi strip $4 \mathrm{~cm} \mathrm{x}$ $0.4 \mathrm{~cm}$, roda gila (flywheel), rantai dan sprocket sepeda bagian belakang, cat, gemuk, 
mur dan baut, pipa pvc 1 inch, stop cran 1 inch, air, dan empulur batang sagu sebagai bahan yang akan diekstrak.

Peralatan yang digunakan yaitu timbangan, stop watch, gergaji besi, chain saw, bor besi, peralatan las listrik, tacho meter , ember, blender, saringan, parang, kampak, gurinda, berbagai jenis obeng, kunci pas, tang, mesin bubut, drilling machine, band saw, dan berbagai peralatan bengkel lainnya untuk pembuatan mesin pengekstrak.

\section{Desain fungsional}

Bagian/komponen fungsional (process system) dari mesin pengekstrak ini berupa tabung pengaduk sekaligus pemeras. Bagian pengaduk (stirrer) berupa poros yang dipasangi bilah (blade) pengaduk secara radial yang berfungsi untuk melepaskan butiran pati dari ampas. Susunan bilah pengaduk diatur sedemikian rupa agar pengadukan dapat berlangsung secara efektif. Pada dasar tabung terdapat saringan (screen) yang berfungsi untuk memisahkan pati dengan ampas. Bagian bawah tabung berbentuk corong yang berfungsi untuk memperlancar aliran keluar suspensi pati sekaligus menghindari terjadi endapan pati di dasar tabung.

Evaluasi kinerja mesin dilakukan dengan 2 parameter variabel bebas yaitu (a). Rasio antara diameter driver pulley:driven pulley, terdiri dari 3 level yaitu: 3:1 (rpm1), 4: 1 (rpm2) dan 6: 1 (rpm3) (b). Waktu pengadukan terdiri dari 3 taraf yaitu 5 menit (t1), 10 menit (t2), dan 15 menit (t3). Dengan demikian terdapat 9 kombinasi perlakuan yang diuji, masing-masing diulang 3 kali sehingga ada 27 unit percobaan.

\section{Desain struktural}

Mesin pengekstrak pati ini (Gambar 1) terdiri dari 5 bagian utama yaitu: (1) Rangka utama (Frame), (2) Mekanisme penggerak pengaduk (berupa rantai, sproket, pulley, dan V-belt, serta pedal), (3) Tabung pengekstrak (terbuat dari plat stainless yang dibentuk menjadi tabung, pada dasar tabung dibuat berbentuk corong agar tidak terjadi endapan pati di dasar tabung), (4). Pipa penyalur pati (berupa pipa PVC 1 inch yang dilengkapi dengan stop kran, (5) Pengaduk (stirrer).

Tabung pengekstrak berdiameter 30 $\mathrm{cm}$, panjang $60 \mathrm{~cm}$ (volume tabung: 40 liter), terbuat dari plat stainless steel $2 \mathrm{~mm}$. Pada dasar tabung dipasangi saringan (screen) yang berfungsi untuk menyaring pati. Bagian pengaduk terdiri dari poros berdiameter 25 $\mathrm{mm}$ yang dipasangi bilah (blade) pengaduk secara radial. Posisi tabung pengaduk diletakkan secara horizontal.

Rangka utama (frame), berfungsi untuk mendukung dan sekaligus merupakan dudukan bagian-bagian lainnya. Frame terbuat dari besi siku berukuran $5 \mathrm{~cm} \mathrm{x} 5 \mathrm{~cm}$ $\mathrm{x} 0.5 \mathrm{~cm}$, dan besi strip. Penyambungan dilakukan dengan pengelasan dan sebagian menggunakan mur dan baut.

Komponen transmisi daya (power transmision) menggunakan rantai, sprocket, pulley dan V-belt. Tenaga dari operator disalurkan dari pedal ke poros driver menggunakan rantau dan sprocket untuk kemudian diteruskan ke poros pengaduk dengan pulley dan V-belt. Kecepatan putar pengaduk tergantung pada rasio driver pulley:driven pulley serta kekuatan operator. Untuk memperoleh momen gaya (torsi) yang besar dan agar putaran pengaduk konstan (smooth), maka pada poros pengaduk dan poros driver pulley dilengkapi dengan roda gila(flywheel). 


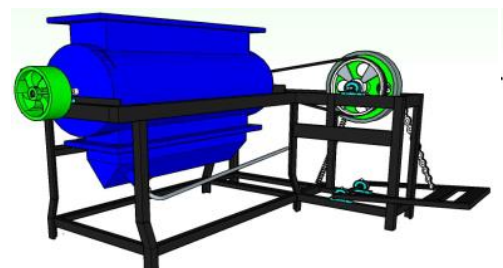

$\mathbf{a}$

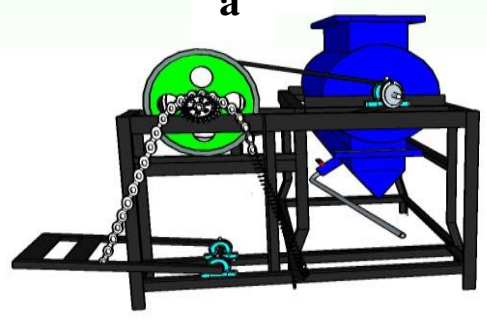

c

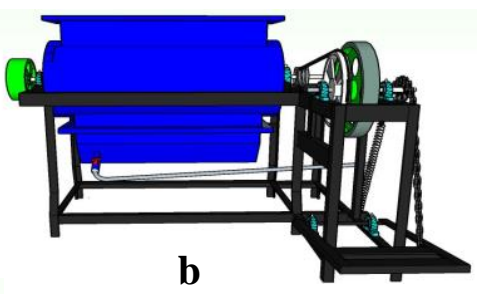

b

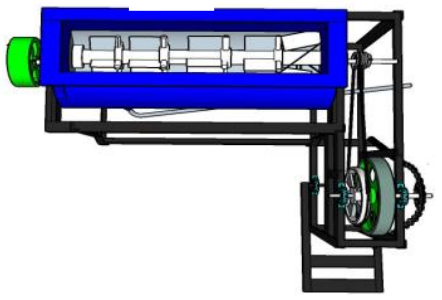

d

Gambar 1. Konstruksi mesin pengekstrak pati sagu tipe stirrer rotary blade (a) Tampak SW isometric, (b) Tampak depan, (c) Tampak samping, (d) Tampak atas.

\section{Variabel Pengamatan}

Evaluasi kinerja untuk setiap perlakuan (independent variable) dilakukan dengan mengukur variable pengamatan (dependent variable): (a) Kapasitas ekstraksi, (b) Rendemen pati, (c) Hasil pati, dan (d) Persentase kehilangan pati pada ampas.

\section{(a) Kapasitas ekstraksi}

Sebelum proses ekstraksi, empulur batang sagu terlebih dahulu dihancurkan dengan menggunakan mesin parut sagu tipe silinder (Darma dkk., 2009). Hancuran empulur batang hasil parutan (ela/rasped pith) kemudian ditimbang $(m E)$ lalu dimasukkan ke tabung pengekstrak. Massa ela untuk setiap proses adalah $10 \mathrm{~kg}$ dengan waktu ekstraksi ( $t)$ sesuai perlakuan. Kapasitas ekstraksi $(K E)$ dihitung dengan persamaan (1):

$$
K E=\frac{m E(\mathrm{~kg})}{t(\mathrm{jam})}
$$

\section{(b) Rendemen pati}

Pati hasil ekstraksi ditimbang massanya $(m P)$ dan dibagi dengan massa ela yang diproses $(m E)$. Rendemen pati $(R d)$ diperoleh dengan menggunakan persamaan (2):

$$
R d=\frac{m P(k g)}{m E(k g)} \times 100 \%
$$

\section{(c) Hasil pati (starch yield)}

Hasil pati tergantung pada kapasitas ekstraksi dan rendemen pati, merupakan hasil kali dari kapasitas ekstraksi (KE) dan rendemen pati $(R d)$. Jadi hasil pati $(S Y)$ dihitung dengan menggunakan persamaan (3):

$$
S Y=R d \times S Y
$$

\section{(d) Persentase pati pada ampas}

Untuk menilai efektivitas proses ekstraksi, sampel ampas sagu diekstrak kembali (re-extract) secara manual sampai benar-benar tidak ada lagi pati yang terdapat pada ampas yang ditandai dengan air perasan jernih. Pati hasil ekstraksi ulang ini ditimbang massanya $(m P A)$ dan dibagi dengan massa ampas $(m A)$ untuk mengetahui persentase pati yang tidak terekstrak. Persentase pati pada ampas ( $P A)$ dihitung menggunakan persamaan (4):

$$
R A=\frac{m P A(k g)}{m A(k g)} \times 100 \%
$$

\section{Analisis data}

Data dianalisis secara tabulasi dan disajikan dalam bentuk gambar dan grafik. 


\section{HASIL DAN PEMBAHASAN}

\section{Konstruksi dan Pengoprasian Mesin Pengekstrak Pati Sagu Tipe Stirrer Rotary Blade Bertenaga pedal}

Konstruksi dan pengoprasian mesin pengekstrak yang telah dihasilkan pada penelitian ini ditampilkan pada Gambar 2. Pengoperasian mesin dilakukan menggunakan tenaga manusia, diawali dengan memasukkan hancuran empulur sagu (ela) kedalam tabung pengekstrak lalu memutar poros pengaduk dengan menginjak pedal. Tenaga dari pedal ditransmisikan ke as pulley penggerak (driver pulley) menggunakan rantai dan sproket. Gerak osilasi dari tuas pedal dirubah menjadi gerak rotasi pada poros pulley penggerak. Selanjutnya tenaga ditrasmisikan ke poros pengaduk menggunakan pulley dan V-belt. Kecepatan putar poros pengaduk tergantung pada rasio driver pulley:driven pulley. Semakin besar rasio tersebut maka kecepatan putar poros pengaduk semakin tinggi. $\quad \mathrm{Ke}$ dalam tabung juga ditambahkan air secukupnya yang berfungsi melepaskan pati dan kemudian mengalirkannya ke bak penampung. Selama proses ekstraksi berlangsung, air dialirkan secara terusmenerus ke dalam tabung, bisa menggunakan pompa atau aliran secara gravitasi dari wadah penampungan air.
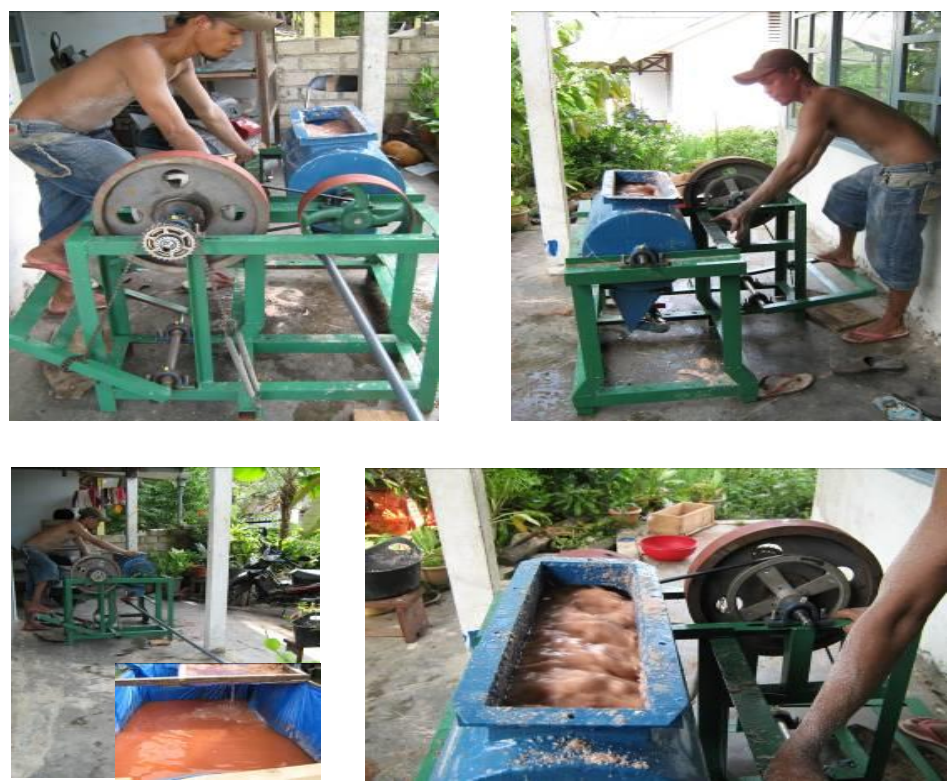

Gambar 2. Pengoprasian mesin pengekstrak pati sagu tipe stirrer rotary blade (a, b), bak pengendapan pati (c) dan pola aliran bahan dalam silinder ekstraksi (d).

\section{Kapasitas Ekstraksi}

Pati pada batang sagu berada dalam sel-sel empulur dalam bentuk tidak terbebas (unfreed starch). Untuk membebaskan pati sagu, sel-sel empulur sagu harus dihancurkan baik secara manual maupun secara mekanis agar pati dapat dipisahkan dari komponen lainnya pada proses ekstraksi. Saat ini pada umumnya penghancuran empulur dilakukan menggunakan mesin parut sagu (sago rasper). Semakin halus butiran hancuran empulur sagu (rasped pith/ela), semakin tinggi pati yang dihasilkan. Namun di sisi lain, semakin halus butiran ela mengakibatkan proses pemisahan pati dari ampas menjadi lebih sulit (Colon and Annokke, 1984; Cecil, 1992). Setelah proses pemarutan, pati yang terkandung dalam empulur terbebas (free state) sehingga dapat dipisahkan pada proses ekstraksi.

Pada Gambar 3 disajikan kapasitas ekstraksi pada berbagai rasio driver pulley terhadap driven pulley dan periode waktu ekstraksi. 


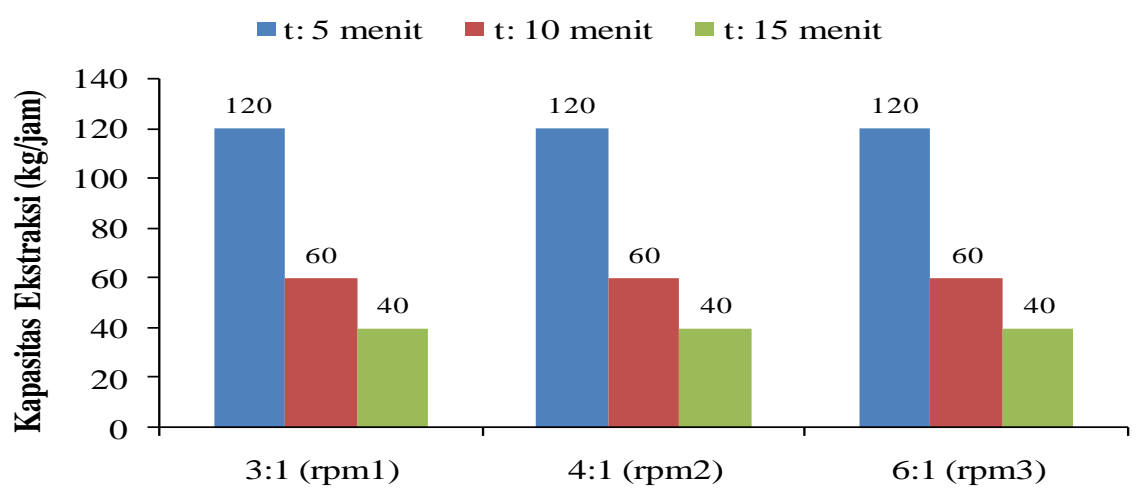

Ratio Driver Pulley terhadap Driven pulley

Gambar 3. Kapasitas ekstraksi pada berbagai ratio driver pulley: driven pulley dan periode waktu ekstraksi

Kapasitas ekstraksi adalah jumlah ela yang diproses/diekstraksi per satuan waktu tertentu (jam). Proses ekstraksi diawali dengan memasukkan $10 \mathrm{~kg}$ ela ke dalam tabung ekstraksi untuk setiap proses dengan lama waktu sesuai perlakuan yaitu 5, 10 dan 15 menit. Dari Gambar 5 terlihat bahwa kapasitas ekstraksi berbanding terbalik dengan periode waktu ekstraksi, semakin lama waktu proses ekstraksi maka semakin kecil kapasitas ekstraksi. Dalam penelitian ini Kapasitas ekstraksi tidak tergantung pada ratio driver pulley: driven pulley karena proses ekstraksi dihentikan hanya berdasarkan pada waktu ekstraksi tanpa memperhatikan faktor lain. Jadi kapasitas ekstraksi hanya tergantung pada periode waktu pengadukan. Waktu yang diperlukan untuk sekali proses terdiri dari: (a) pemasukan bahan ke dalam tabung ekstraksi, (b) Pengadukan, peremasan dan penyaluran suspensi pati ke dalam bak pengendapan pati (c) Pengeluaran ampas dari dalam tabung ekstraksi. Pada periode waktu 2 menit awal, pengadukan dan peremasan berlangsung tanpa mengalirkan suspensi pati ke bak pengendapan. Pada periode ini juga tidak dialirkan air ke dalam tabung ekstraksi. Setelah 2 menit, kran pada ujung pipa penyalur dibuka dan suspensi pati mengalir ke dalam bak pengendapan pati. Selama pengaliran suspensi pati dari dalam tabung ekstraksi ke bak pengendapan, sangat penting untuk memperhatikan bahwa jumlah air yang dialirkan ke dalam tabung seimbang (ballance) dengan aliran keluar agar proses berlangsung lancar. Jumlah aliran dari dalam tabung dikontrol dengan mengontrol besar kecilnya bukaan katup pada stop kran. Semakin besar debit air yang digunakan semakin efektif proses pemisahan pati dari ampas. Jika debit air yang digunakan terlalu sedikit, proses pemisahan pati tidak efektif dan banyak pati yang terbuang bersama ampas karena tidak terekstrak, sebaliknya jika terlalu banyak air yang digunakan maka biaya operasional lebih mahal (Cecil 1992). Faktor lain yang penting untuk diperhatikan adalah perbandingan debit air yang dimasukkan ke dalam tabung ekstraksi dengan debit aliran suspensi pati yang keluar (dialirkan ke bak pengendapan) harus seimbang. Jika jumlah aliran masuk lebih kecil dari aliran ke luar, suspensi material (slurry) dalam tabung ekstraksi menjadi lebih kental dan lebih sulit untuk diaduk dan diperas. Pada kondisi ekstrim dapat mengakibatkan kemacetan pada pengaduk akibat kelebihan beban (over load) bahkan dapat mengakibatkan kerusakan pada komponen mesin ekstraksi. Sebaliknya jika jumlah air yang dialirkan ke dalam tabung lebih besar dari aliran ke luar, maka air akan meluap melalui permukaan atas tabung.

Dari hasil pengukuran sebagaimana terlihat pada Gambar 3. diperoleh kapasitas ekstraksi tertinggi $120 \mathrm{~kg}$ ela/jam. Kapasitas ekstraksi tersebut lebih rendah jika dibandingkan dengan mesin ekstraksi sejenis bertenaga motor bakar yang dihasilkan pada penelitian Darma dkk., (2010; 2014; 2015; 2017) yang memiliki kapasitas ekstraksi berturut-turut $140 \mathrm{~kg}$ ela per jam, $204 \mathrm{~kg}$ per 
jam, $209 \mathrm{~kg}$ per jam dan $222 \mathrm{~kg}$ per jam. Alat pengolahan sagu mekanis sistim terpadu hasil rancangan Balai Penelitian Kelapa dan Palma lain (BALITKA) bekerjasama dengan ALSINTANI Serpong memiliki kapasitas ekstraksi $190 \mathrm{~kg}$ empulur/jam ( Badan Penelitian dan Pengembangan Pertanian, Pusat Penelitian dan Pengembangan Perkebunan, 2001). Alat pengolahan sagu hasil rancangan BPPT (1990) berkapasitas $500 \mathrm{~kg}$ empulur per proses. Lebih rendahnya kapasitas ekstraksi yang dihasilkan pada penelitian ini disebabkan karena sumber tenaga penggerak yang digunakan yaitu tenaga manusia kekuatannya/daya jauh lebih rendah dibandingkan dengan mesin ekstraksi pati bertenaga motor bakar sehingga kapasitas daya tampung tabung ekstraksi

\section{Rendemen Pati dan Persentase Pati pada Ampas}

dibuat lebih kecil. Namun jika dibandingkan dengan metode ekstraksi secara tradisional, kapasitas ekstraksi yang dihasilkan pada penelitian ini jauh lebih tinggi. Laelaem (2017) dan Selano (2017) melaporkan bahwa kapasitas ekstraksi secara tradisional di daerah Masni SP-7 sebesar 30,5 kg per jam. Darma (2011) melaporkan bahwa pada pengolahan sagu secara tradisional oleh masyarakat papua, waktu yang diperlukan untuk mengolah 1 pohon rata-rata 41 jam atau 6 hari kerja dengan jumlah tenaga kerja yang terlibat 2-3 orang. Sebagian besar waktu pengolahan yaitu 20 jam tercurah untuk penghancuran empulur (tokok) dan 18 jam untuk ekstraksi (ramas sagu) dengan kapasitas ekstraksi antara 30-40 $\mathrm{kg} / \mathrm{jam} /$ orang.

Pada Gambar 4 dan Gambar 5 berturut-turut disajikan rendemen pati dan persentase pati pada ampas pada berbagai periode waktu ekstraksi dan ratio driver pulley:driven pulley.

t1:5 menit $\quad$ t2:10 menit $\quad$ t3: 15 menit

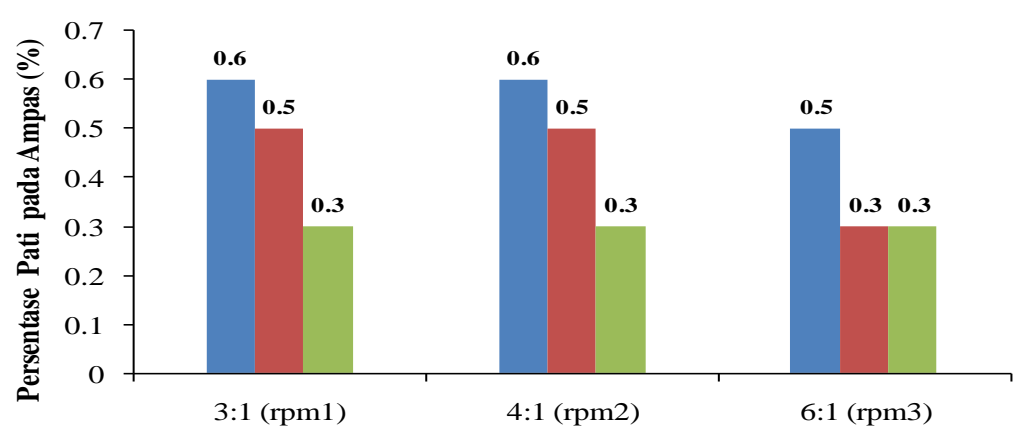

Ratio Driver Pulley terhadap Driven pulley

Gambar 4. Rendemen pati pada berbagai ratio driver pulley: driven pulley dan periode waktu ekstraksi

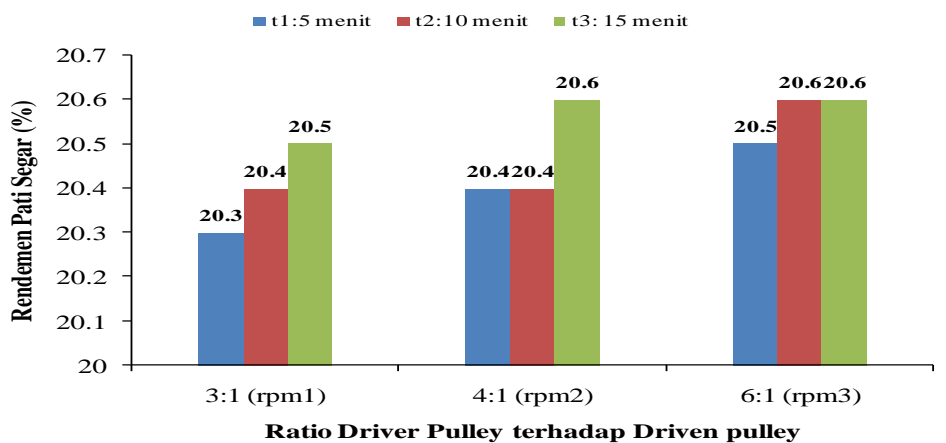

Gambar 5. Persentase pati terikut ke ampas pada berbagai ratio driver pulley: driven pulley dan periode waktu ekstraksi 
Dari Gambar 4 memperlihatkan bahwa terjadi sedikit peningkatan rendemen pati dengan meningkatnya periode waktu ekstraksi, semakin lama periode waktu ekstraksi maka semakin tinggi rendemen pati. Demikian pula halnya dengan peningkatan rpm sebagai akibat dari peningkatan ratio driver pulley: driven pulley meningkatkan rendemen pati. Hal ini disebabkan karena semakin lama proses ekstraksi berlangsung, semakin banyak jumlah pati yang terekstrak sehingga pati yang tertinggal pada ampas semakin sedikit. Sama halnya dengan peningkatan rpm pengaduk, mengakibatkan peningkatan efektivitas pemisahan pati dari ampas sehingga meningkatkan rendemen pati. Hasil ini sejalan dengan hasil penelitian terdahulu dengan menggunakan mesin ekstraksi pati bertenaga motor bakar. (Darma dkk., 2010; 2014; 2015; 2017).

Rendemen pati yang dihasilkan pada penelitian ini $(20.3$ - $20.6 \%)$ konsisten dengan hasil penelitian sebelumnya (Darma dkk., 2009; 2010; 2011; 2014; 2015) yangmana menghasilkan rendemen pati berturut-turut $18,05 \%, 15,84 \%$. $11.3 \%$; $20.54 \%$; 24\%, namun lebih rendah dibandingkan dengan hasil penelitian Darma dkk. (2017) yang menghasilkan rendemen pati $49 \%$. Hal ini terutama disebabkan karena faktor kandungan pati (starch content) pada batang sagu yang diproses. Tingginya variasi rendemen pati yang dihasilkan oleh peneliti yang berbeda, di samping dipengaruhi oleh teknik pengolahan yang digunakan, juga dipengaruhi oleh kandungan pati pada empulur batang sagu. Alat pengolahan sagu mekanis sistim terpadu hasil rancangan Balai Penelitian Kelapa dan Palma Lain (BALITKA) bekerjasama dengan ALSINTANI Serpong menghasilkan rendemen pati 24 - 30,7 \%, ( Badan Penelitian dan Pengembangan Pertanian, Pusat Penelitian dan Pengembangan Perkebunan, 2001), sedangkan alat pengolahan sagu hasil rancangan BPPT (1990) menghasilkan rendemen pati sekitar 12.7 - $14 \%$. Hasil penelitian Darma dkk., (2004; 2011), menjumpai bahwa kadar pati sagu diberbagai lokasi di Papua berkisar antara $12.43 \%-39.89 \%$. Hasil penelitian Worabai (2011) menghasilkan rendemen pati $38,09 \%$. Hasil penelitian Reniana (2008), memperoleh rendemen pati antara $34 \%-37$
\%. Paulinus (2005) melaporkan adanya jenis sagu di Kabupaten Merauke dengan kadar pati segar mencapai $56 \%$. Menurut Flach (1997), kandungan pati pada empulur batang berkisar antara $10 \%$ sampai $25 \%$, sedangkan menurut BPPT (1992), kandungan pati pada empulur batang bervariasi, tergantung pada umur, jenis, dan lingkungan tempat tumbuh. Menurut Haryanto dan Pangloli (1992), kandungan pati dalam empulur batang berbeda-beda tergantung dari umur, jenis dan lingkungan tempat tumbuh. Rendemen pati hasil pengolahan secara tradisional yang dilakukan oleh masyarakat di Propinsi Papua berkisar antara 11\% - 31,2 \% (Darma, 2011).

Dari Gambar 5 terlihat bahwa persentase pati yang terikut ke ampas cenderung menurun dengan meningkatnya waktu pengadukan. Peningkatan rpm pengaduk juga menurunkan persentase pati pada ampas. Hal ini terkait dengan peningkatan efektivitas ekstraksi dengan meningkatnya rpm pengaduk. Gambar 5. juga memperlihatkan bahwa persentase pati yang masih terikut ke ampas sangat rendah yaitu berkisar dari 0,3\%-0,6\%. Hal ini berarti bahwa proses ekstraksi pada semua perlakuan berlangsung efektif. Hasil ini konsisten dengan hasil penelitian (Darma dkk., 2010; Darma dkk.,2011) yang menghasilkan pati pada ampas berturut-turut sebesar 0,457\% dan $0,675 \%$, namun lebih rendah dibandingkan dengan hasil penelitian Darma dkk. (2014) dan (2017) dengan persentase pati pada ampas berturut-turut $2 \%$ dan 2,4 $5.5 \%$. Persentase pati yang masih terikut ke ampas hasil pengolahan secara tradisional yang dilakukan oleh masyarakat Papua adalah 9,3\% (Darma, 2011). Hasil penelitian Selano (2017) memperoleh persentase pati pada ampas pada pengolahan secara tradisonal di Kampung Masni Manokwari adalah $3.5 \%$ Hasil pengamatatan yang dilakukan oleh Cecil dkk., (1982) pada beberapa industri sagu komersil di Serawak Malaysia menunjukkan bahwa rata-rata pati yang terikut ke ampas (hampas) berkisar antara 18,2 \% - $25 \%$.

\section{Hasil Pati (starch yield)}


Pada Gambar 6 ditampilkan hasil pati ratio driver pulley:driven pulley. pada berbagai periode waktu ekstraksi dan

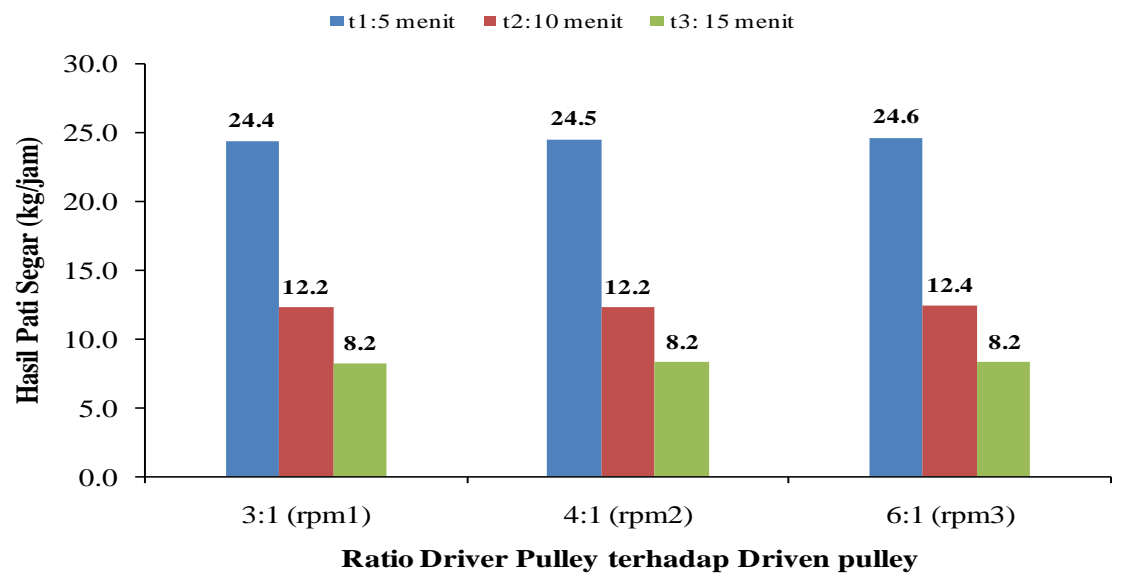

Gambar 6. Hasil pati pada berbagai ratio driver pulley: driven pulley dan periode waktu ekstraksi.

Dari Gambar 6 terlihat bahwa semakin lama periode waktu ekstraksi, semakin rendah jumlah pati yang dihasilkan per jam. Hal ini terkait dengan kapasitas ekstraksi semakin rendah dengan semakin meningkatnya waktu ekstraksi. Walaupun terjadi sedikit peningkatan rendemen pati dengan meningkatnya waktu ekstraksi (Gambar 4) namun karena peningkatannya tidak begitu tajam dibandingkan dengan penurunan kapasitas ekstraksi maka konsekuensinya hasil pati berbanding terbalik dengan periode waktu ekstraksi. Hal ini juga berarti bahwa hasil pati lebih dipengaruhi oleh kapasitas ekstraksi daripada rendemen pati. Hasil pati tertinggi $(24 \mathrm{~kg} / \mathrm{jam})$ lebih rendah dari hasil penelitian Darma dkk., (2010); Darma dkk., (2014); Darma dkk., (2017) yang memperoleh hasil pati berturutturut $33 \mathrm{~kg} / \mathrm{jam}, 79 \mathrm{~kg} / \mathrm{jam}$ dan $100 \mathrm{~kg} / \mathrm{jam}$. Hasil pati tergantung pada metode ekstraksi yang digunakan dan kadar pati pada empulur batang (Cecil, 1992). Kapasitas ekstraksi sangat tergantung pada kapasitas tampung tabung pengekstrak, sumber tenaga penggerak dan lamanya waktu pengadukan. Dari hasil pengujian dijumpai bahwa kapasitas tampung tabung pengekstrak adalah $10 \mathrm{~kg}$ empulur per sekali proses, sedangkan waktu pengadukan cukup 5 menit saja karena dengan waktu tersebut lebih dari $99 \%$ kandungan pati telah terekstrak. Penambahan waktu lebih lanjut hanya akan membuang-buang waktu, tenaga dan biaya oprasional.

\section{KESIMPULAN}

Dari hasil penelitian ini, telah dihasilkan prototype mesin pengekstrak pati sagu tipe stirrer rotary blade bertenaga pedal dengan kinerja yang baik. Mekanisme kerja dari mesin ini mengkombinasikan peremasan dan pengadukan sehingga melepaskan pati dari ampas dan tersuspensi ke dalam air untuk kemudian dipisahkan dari ampas melalui saringan. Semakin singkat periode waktu pengadukan dan semakin besar ratio driver pulley:driven pulley maka semakin tinggi kinerja mesin. Kinerja terbaik dihasilkan pada ratsio driver pulley:driven pulley 6:1 dengan periode waktu pengadukan 5 menit. Kinerja mesin pada kondisi tersebut adalah (a) Kapasitas ekstraksi $120 \mathrm{~kg}$ ela/jam, (b) Rendemen pati $20,6 \%$, (c) Hasil pati 24,6 kg/jam dan (d) Persentase pati pada ampas $0,3 \%$.

\section{DAFTAR PUSTAKA}

Badan Penelitian dan Pengembangan Pertanian Pusat Penelitian dan Pengembangan Perkebunan. 2001. Potensi, Penyebaran, dan Alat Pengolahan Sagu Sistim Terpadu. Pusat Penelitian dan Pengembangan Perkebunan. Bogor.

Bintoro, M.H, (2011), Progress of sago research in Indonesia. In: Proc $10^{\text {th }}$ int sago symposium: sago for food 
security, bio-energy, and industry from research to market. Bogor, pp 16-34.

BPPT. $\quad 1990 . \quad$ Pengkajian dan Pengembangan Peralatan Pengolahan Sagu. BPP Teknologi. Bogor.

Cecil, J.E, (1992), Small-, medium-and largescale starch processing. Rome: FAO Agricultural Services Bulletin 98.

Cecil, J.E, Lau G., Heng H, and Ku C.K., (1982), The sago starch industry: a technical profile based on preliminary study made in Sarawak. London: Tropical Product Institute.

Colon, F.J. and Annokke, G.J., (1984), Survey of some processing route of sago. In: Proc. the expert consultation of the sago palm and palm products. Jakarta, Indonesia, January 16-21.

Darma, (2011), Traditional processing of sago in Papua Province. In Proc $10^{\text {th }}$ int sago symposium: sago for food security, bio-energy, and industry from research to market. Bogor, 29-31 October, pp 115-116.

Darma, (2009), Prototype of cylinder type sago rasper powered by $5.5 \mathrm{hp}$ gasoline engine. Agrotek Journal 1(6):49-56.

Darma, and T. Worabai, (2010), Variant-1 of cylinder type sago rasper powered by $5.5 \mathrm{hp} \mathrm{Gasoline} \mathrm{Engine.} \mathrm{Agrotek} \mathrm{J}$ 2(3):82-90.

Darma, P. Istalaksana, and A. Gani, (2010) Prototype of stirrer rotary blades type sago starch extractor. Agritech J 30(4):204-211.

Darma, (2010). Starch content and production potency of natural sago palm (Metroxylon sagu Rottb). Agrotek J 2(2):7-14

Darma, Wang X, and Kito K. (2013) Improvement of cylinder type sago rasper using sharp teeth. In Proc $11^{\text {th }}$ int sago symposium: Unleashing Sago, Hidden Treasure of the World. Manokwari, 6-8 November, pp 79-90.

Darma, Xiulun Wang, and Koji Kito, 2014,. Development of Cylinder Type Sago Rasper for Improving Rasping Performance. International Agricultural Engineering Journal (IAEJ) Vol. 23, No.3:31-40.

Darma, Xiulun Wang, Koji Kito, 2014, Development of Sago Starch Extractor with Stirrer Rotary Blade for Improving Extraction Performance. International Journal of Engineering and Technology (IJET) Vol. 6, No.5: 2472-2481.

Darma dan Triyanto Budi. 2015. Development and Performance Test of Cylinder Type Sago Rasper Powered by Petrol Engine. Prosiding Seminar Nasional PERTETA 5-7 Agustus, 2015. Universitas Hasanuddin. Makassar.

Darma, Xiulun Wang, and Koji Kito, 2015, Effect of Teeth Density and Cylinder Rotation Speed on Power Requirement and Specific Energy Consumption of Cylinder Type Sago Rasper in: Prooceedings of the $12^{\text {th }}$ International Sago Symposium September 15 17, 2015. Tokyo, Japan.

Darma dan Sumartono. 2015. Pemberdayaan dan Pengembangan Industri Pengolahan Pati Sagu Rakyat di Kabupaten Teluk Wondama, Papua Barat. Laporan Program Insentif Diseminasi Produk Teknologi ke Masyarakat. LPPM Unipa. Manokwari.

Darma dan A. Kurniawan. 2016. Effect of Cylinder Rotation Speed, Teeth Density and Engine Power Rate on Performance of Cylinder Type Sago Rasping Machine. in: The $1^{\text {st }}$ international conference : The role of agricultural engineering for sustainable agricultural production (AESAP). 1314 Desember, 2016, IPB Bogor.

Darma, B. Santoso, Reniana. 2017. Development of cylinder type sago rasping machine using pointed teeth. International Journal of Engineering and Technology (IJET-IJENS) Vol. 17, No.01: 2472-2481.

Darma dan B. Santoso. 2017. Variant-3 Mesin Ekstraksi Pati Sagu Tipe Stirrer Rotary Blade Bertenaga Motor Bakar Bensin. Dalam: Prosiding Seminar Nasional Hasil Penelitian Inovasi Teknologi Pertanian. Sorong 8-9 November 2017

Haryanto, B dan P. Pangloli. 1992. Potensi Dan Pemanfaatan Sagu. Kanisius. Jokyakarta. 
Jong, F. S. and C.J. Hoo. 2011. Growth and Yields of Natural Sago Forests for commercial operations. In Proc. $10^{\text {th }}$ Int.Sago Symposium, Sago for food security, Bio-energy, and Industry from Research to Market, 43-45. Bogor, Indonesia, Oct. 29-31.

Laelaem, V.C. 2017. Studi Pengolahan Sagu (Metroxylon sp) Secara Semi Mekanis di Kampung Masni Distrik Masni Kabupaten Manokwari. Skripsi Fakultas Teknologi Pertanian UNIPA. Manokwari.

Matanubun H, Maturbongs L (2006) Sago palm potential, biodiversity and sociocultural consideration for industrial sago development in Papua, Indonesia. In Proc. $8^{\text {th }}$ Int. Sago Symposium: Sago Palm Development and Utilization, Jayapura, pp 41-54.

Paulinus, K. 2005. Studi Pengolahan Sagu Secara Tradisional di Kabupaten Merauke Papua. Fakultas Pertanian dan Teknologi Pertanian UNIPA. Manokwari.

Selano, M.M. 2017. Uji Lapang dan Analisis Ekonomi Mesin Parut Sagu Tipe Silinder Bertenaga Motor Bakar. Skripsi Fakultas Teknologi Pertanian UNIPA. Manokwari. 